\title{
Management of rheumatoid arthritis: Impact and risks of various therapeutic approaches (Review)
}

\author{
CAROLINA NEGREI $^{1}$, VIOLETA BOJINCA ${ }^{2}$, ANDRA BALANESCU ${ }^{2}$, MIHAI BOJINCA ${ }^{3}$, \\ DANIELA BACONI ${ }^{1}$, DEMETRIOS A. SPANDIDOS ${ }^{4}$, ARISTIDIS M. TSATSAKIS ${ }^{5}$ and MIRIANA STAN ${ }^{1}$ \\ ${ }^{1}$ Department of Toxicology, Faculty of Pharmacy, 'Carol Davila' University of Medicine and Pharmacy, \\ Bucharest 020956; ²Department of Internal Medicine and Rheumatology, 'Sfanta Maria' Hospital, \\ Bucharest 011172; ${ }^{3}$ Department of Internal Medicine and Rheumatology, 'Ion Cantacuzino' Hospital, \\ Bucharest 020475, Romania; ${ }^{4}$ Department of Clinical Virology, School of Medicine, ${ }^{5}$ Department of Forensic \\ Sciences and Toxicology, Faculty of Medicine, University of Crete, Heraklion 71003, Greece
}

Received December 10, 2015; Accepted February 2, 2016

DOI: 10.3892/etm.2016.3045

\begin{abstract}
Rheumatic diseases are highly prevalent chronic disorders and the leading cause of physical disability worldwide, with a marked socio-economic impact. Rheumatoid arthritis (RA) is a chronic systemic inflammatory disease of unknown etiology with an autoimmune pathogenesis, characterised by arthropathy with chronic, deforming, destructive evolution and multiple systemic manifestations. The management of RA has undergone significant changes as far as objectives and approaches are concerned, ending in the current strategy known as 'treat to target'. The therapeutic array of RA includes several categories of medicinal products, of varying potential. There are several criteria for the classification of medicinal products used against this disease, one of the most important and modern of which divides such substances according to their effects on the progress of the disease: symptom-modifying antirheumatic drugs (including non-steroidal anti-inflammatory drugs and corticoids), disease-modifying antirheumatic drugs (including various substances, such as gold salts, antimalarials, sulfasalazine, D-penicillamine; non-specific immunosuppressive medication, such as methotrexate, cyclophosphamide, azathioprine and leflunomide) and biological therapy is a recent addition, providing new insight into the treatment of this disease. The selection of the optimal therapy for RA should be based on guidelines and recommendations, but also on clinical particular aspects and patient preferences.
\end{abstract}

Correspondence to: Dr Violeta Bojinca, Department of Internal Medicine and Rheumatology, 'Sfanta Maria' Hospital, 37-39 Ion Mihalache Boulevard, Bucharest 011172, Romania

E-mail:vmbojinca@yahoo.com

Key words: rheumatoid arthritis, treatment, disease-modifying antirheumatic drugs, biological therapy

\section{Contents}

1. Introduction

2. Treatment classification

3. Conclusions

\section{Introduction}

Rheumatoid arthritis (RA) is a chronic inflammatory disease of unknown etiology and autoimmune pathogeny, involving the joints and is accompanied by severe deformity and destruction, resulting from inflammation and hypertrophy of the synovial membrane of the diarthrodial joints (synovitis). RA may be complemented with multiple systemic characteristics. The management of RA has undergone significant changes as far as objectives and approaches are concerned, ending in the current strategy known as 'treat to target'. The primary objective of this in patient treatment is the immediate control of inflammation, through a potentially 'aggressive' approach, aiming to prevent progressive structural lesions, maximise the long-term quality of life through symptom control, optimise articular function and improve social inclusion. The treatment of RA involves the use of multiple classes of drugs, each with varying effects (1-3).

\section{Treatment classification}

Non-steroidal anti-inflammatory drugs (NSAIDs). Currently, in spite of very common use either as continuous or as intermittent treatment, NSAIDSs are no longer indispensable RA medication $(1,4)$. Even though they are used to control joint pain and swelling, NSAIDs are not effective in preventing structural damage; it has thus been determined that the use of NSAIDs in the treatment of RA should be in conjunction with drugs with disease-remitting activity. Nevertheless, the long-term use of NSAIDs is frequent in RA, which is associated with various adverse events and increased morbidity and mortality. The mechanisms of action of NSAIDs are based on the inhibition of cyclooxygenase 1 and 2 and the decrease in prostaglandin 
production, which accounts for the adverse effects of NSAIDs. These adverse effects most frequently include gastrointestinal symptoms, such as nausea, dyspepsia, heartburn, abdominal pain, gastritis and peptic ulcers with or without perforation or bleeding. Endoscopic gastric and duodenal ulcerations are present in $30-50 \%$ of NSAID-treated patients $(1,4)$. The use of NSAIDs should be avoided in patients with active ulcers or gastritis, as is treatment with proton pump inhibitors in patients with a history or increased risk of superior digestive complications [e.g., Helicobacter pylori infection, increased alcohol intake, the concomitant administration of aspirin, clopidogrel, anticoagulants and glucocorticoids (GCs)] $(1,4)$.

As regards long-term treatment with NSAIDs, cardiovascular adverse effects are also prominent, as evidenced by multiple reports of oedema, the aggravation of hypertension and/or heart failure and the increased risk of thrombotic events, including myocardial infarction. In patients with previous, even controlled, cardiovascular problems, with severe cardiovascular disease or risk factors, NSAIDs should be prescribed with caution or even avoided where possible. Chronic kidney disease may also be another complication of long-term NSAID use; the use of these drugs should preferably be avoided or the dose should be adjusted in patients with decreased creatinine clearance (4).

Glucocorticoids. GCs are hormones acting through complex mechanisms, generating genomic and non-genomic effects $(5,6)$. They are characterised by rapid symptomatic effects, and in association with drugs with disease-remitting activity, they also prevent structural damage in early RA. Typically, small doses are indicated $(<7.5 \mathrm{mg}$ prednisone or equivalent/day in the first 6 months of treatment). In remissive patients, the use of GCs should be tapered and terminated where possible, as the long-term use of GCs is associated with multiple adverse effects.

The use of GCs is also indicated in rheumatoid vasculitis or other RA systemic manifestations, as well as in severe active forms of RA, until control by remissive therapy becomes possible. GCs may also be used as local treatment for joints or structures not responsive to systemic treatment. In the case of RA, GCs are used in small doses ( $\leq 10 \mathrm{mg} / \mathrm{day})$, average doses (10-30 mg/day), large doses (>30 mg/day) and pulse therapy ( $>250 \mathrm{mg}$ methylprednisolone/day, via infusion) $(5,6)$.

The use of GCs is associated with the occurrence of various adverse events, which may be classified into preventable and non-preventable events. Preventable adverse effects include heart failure, hypertension, osteoporosis, diabetes mellitus, peptic ulcers, myopathy, as well as sleep and mood disturbances. Non-preventable adverse events include cataract, avascular necrosis, cutaneous modifications, accelerated atherosclerosis, infections and weight gain $(5,6)$. One of the most threatening complications of the use of GCs is osteoporosis, affecting both bone formation (decrease) and bone resorption (increase). The trabecular bone is the first to be involved in these effects (5).

The most important measure for the prevention of these adverse effects of GCs is a decrease in the use of GCs, using them only when they will be truly effective and necessary (according to guidelines), while decreasing the dose until the complete, safe discontinuation of GC treatment can occur.
Disease-modifying antirheumatic drugs (DMARDs) are a very heterogeneous class of medications, able to influence RA pathogenic mechanisms for the reduction of articular and systemic inflammation and the cessation of disease progression, structural damage and disability. It is now generally recognised that, given the intense destructive potential of RA in the first 2 years and the irreversible nature of structural damage, the use of DMARDs should be undertaken as early as possible, from the very first day of the positive diagnosis of RA $(1,7)$. DMARDs for use in RA are classified into conventional synthetic DMARDs (csDMARDs) and biologic DMARDs (bDMARDs).

Conventional synthetic DMARDs. This class includes a wide range of drugs of various chemical structures and different therapeutic action, some of which are still partially unknown. The most commonly used DMARDs are methotrexate (MTX), leflunomide (LEF), sulfasalazine (SSZ) and hydroxychloroquine (HCQ), whereas azathioprine, cyclosporine A, gold salts and cyclophosphamide can also be used in special situations only.

Methotrexate. MTX is the gold standard of RA treatment $(1-3,8,9)$; however, the mechanisms of action of this drug are still partially unknown in spite of its being in use for over 25 years in the treatment of RA. MTX competitively and irreversibly inhibits dihydrofolate reductase, the enzyme responsible for the conversion of dihydrofolate into tetrahydrofolate (the active metabolite). This is the mechanism by which MTX blocks DNA, RNA and most protein synthesis in fast-dividing cells, such as in gastrointestinal, medullar and neoplastic cells (8-10). MTX also blocks thymidylate synthase and 5-aminoimidazol-4-carboxamid ribonucleotide transformylase, leading to increased intra- and extracellular adenosine with possible anti-inflammmatory effects. These mechanisms explain only in part the complex effects of MTX in the treatment of RA: the decreased secretion of pro-inflammatory cytokines, such as as tumor necrosis factor- $\alpha$ (TNF- $\alpha$ ), interleukin (IL)-1, IL-6, matrix metalloproteinases, prostaglandins and adhesion molecules (8-12).

In the treatment of RA, MTX is used in doses between 7.5-25 $\mathrm{mg} /$ week, in oral or parenteral administration. The adequate use of MTX in patients with RA is associated with improvement and/or remission, as well as the prevention of structural damage for a significant proportion of patients. In long-term use, MTX treatment in stable doses is generally very well tolerated and safe. The associated administration, not on the same day however, of MTX and folic acid (5-15 mg/week) or folinic acid (leucovorin; $27.5 \mathrm{mg} /$ week), is generally recommended to decrease the adverse events (8). The therapeutic efficacy of MTX may be evaluated by the use of the $1(\mathrm{H})$ nuclear magnetic resonance metabolomics method (13).

As regards the occurrence of various adverse events triggered by the administration of MTX in the context of RA treatment, their vast majority are mild. In that respect, gastrointestinal adverse events are the most frequent (dyspepsia, nausea, vomiting, abdominal pain and anorexia). In rare instances, MTX toxicity produces ulcerative stomatitis or diarrhoea. MTX toxicity is also associated with the occurrence of hepatic fibrosis and cirrhosis (8). Hepatic adverse events are marked 
by elevations in the levels of liver enzymes [transaminases, gamma-glutamyl transferase (GGT) and alkaline phosphatase]. Patients with mild elevations in the levels of these enzymes $[<2 \mathrm{x}$ upper limit of normal (ULN)] should be monitored. In the case of significant elevations in these levels ( $>2-3 x$ ULN), the treatment doses should be reduced or the treatment should be stopped entirely. In such cases, it is important to evaluate the presence of concomitant factors with hepatotoxic potential, such as alcohol, paracetamol, chronic viral B or $\mathrm{C}$ hepatitis and other toxic factors. In the majority of patients without additional risk factors, concomitant therapy with folic acid, initial and periodic liver tests and the adjustment of the dose of MTX are sufficient to control liver toxicity $(8,14,15)$. Patients exhibiting persistent and significant modifications in hepatic tests should be referred to a gastroenterologist for specialist evaluation.

Pulmonary adverse events in MTX treatment include acute interstitial pneumonitis, pulmonary fibrosis and non-cardiogenic pulmonary oedema (8). A chest X-ray should be performed at the beginning of the treatment period and periodic evaluation or the evaluation of acute pulmonary symptoms should also be performed during the treatment period. In the case of acute interstitial pneumonitis, the administration of MTX should be terminated. It is important to differentiate MTX-associated pulmonary adverse events from infectious diseases by means of various tests, including bronchoalveolar lavage.

Haematologic adverse events may also occur, such as neutropenia, megaloblastic anaemia, thrombocytopenia and pancytopenia. Folic acid supplements and periodic blood cell counts are the best methods with which to prevent severe haematologic adverse events. An increase in the erythrocyte volume of $>100 \mathrm{fl}$ without other hematologic modifications may be the first sign of hematologic toxicity due to MTX. Cutaneous adverse events include rash, itching, alopecia and rare cases of multiform erythema or exfoliative dermatitis.

Infectious diseases with common or opportunistic agents may frequently affect patients with RA on MTX treatment (8). Neurologic adverse events may consist of headaches, dizziness, and speech, sight or cognitive impairments (8). MTX treatment is teratogenic even at low doses (labelled category X by the US Food and Drug Administration), and should not be used during pregnancy; treatment should be terminated at least 1-3 months prior to conception (8-10). MTX can be used as monotherapy, but also in combination with other csDMARDs or bDMARDs $(16,17)$.

Leflunomide. The therapeutic action of LEF is not yet fully understood. LEF is an isoxazole derivate converted into the active metabolite, A77 1726, in the submucosal wall of the intestinal tract and after the first hepatic passage $(18,19)$. Its active form blocks dihydroorotate dehydrogenase, the enzyme involved in pyrimidine synthesis, an effect leading to the inhibition of tyrosine kinase and nuclear factor $(N F)-\kappa B$ activation, more significant for activated $\mathrm{T}$ cells. In the usual $20 \mathrm{mg} /$ day dose, LEF is a very effective treatment for moderate or severe forms of RA, in the early and late stages of the disease (18). It is associated with the improvement and/or remission and prevention of structural damage. LEF can either be used as monotherapy or in association with csDMARDs or bDMARDs $(16,18,19)$.

The adverse events associated with LEF are partially similar to those of MTX. Gastrointestinal adverse events include nausea, vomiting, diarrhoea, abdominal pain and dyspepsia. Diarrhoea usually occurs in the first 3 months of treatment and is mild/moderate, but is sometimes significantly prolonged and is associated with weight loss (18). Hepatic adverse events are more frequent in association with MTX (15). Hematologic adverse events, such as leukopenia, thrombocytopenia and pancytopenia are rare (18). Neurologic adverse events are usually mild and include headaches, dizziness anmd paraesthesia (18).

The use of LEF may also be associated with cardiovascular events, such as the aggravation of pre-existing hypertension more than that of new-onset hypertension (18). Cutaneous adverse reactions occur more frequently in the first months of treatment and include rash, itching, skin dryness and rare cases of Stevens-Johnson syndrome (18).

Infections are more frequent during LEF treatment; however, not all of these infections are severe. An active serious infection is a contraindication for the initiation of LEF treatment and any treatment already being administered should be terminated until the infection has been controlled. LEF should not be used during pregnancy and should be terminated 2 years prior to conception.

The more rapid elimination of LEF and its metabolites is obtained using cholestyramine treatment (8 g 3 times daily for 11 days) (18). To prevent the adverse events associated with $\mathrm{LEF}$, it is important to rule out serious infections and perform blood cell count and liver tests (hepatitis B and C included) both at the beginning of the treatment period and during the treatment period $(16,18,19)$.

Sulfasalazine. SSZ is a combination of sulfapyridine and 5-aminosalicilic acid and is used for the treatment of RA and other inflammatory diseases. The mechanisms of action of SSZ are partially known and involve the production of the decreased synthesis of TNF- $\alpha$, IL-1 and IL-6, and the decreased activation of NF- $\kappa \mathrm{B}$, the inhibition of $\mathrm{T}$ lymphocytes and the decreased production of IgGs and rheumatoid factor by B lymphocytes.

SSZ is used in the treatment of RA at doses of 2-3 g/day, either as monotherapy or in conjunciont with csDMARDs and bDMARDs $(10,17,20,21)$.

Gastrointestinal adverse events are the most common, but are usually mild (nausea, anorexia, dyspepsia). Hepatic adverse events consist of a mild/moderate increase in the levels of liver enzymes, which is usually attenuated by decreasing the dose or by temporary terminating the treatment. The cutaneous adverse events of SSZ treatment may be rash, itching, photosensitivity, rare cases of multiform erythema or Stevens-Johnson syndrome. Neurologic adverse events are anxiety, headaches, sleep disturbances and irritability.

The main hematologic adverse events are lymphopenia and neutropenia (with rare but serious cases of agranulocytosis in the first 6 weeks of treatment) (21) and rare cases of megaloblastic anaemia. Lymphopenia and neutropenia are indications for the discontinuation of treatment. Rare cases of eosinophilic pneumonia have been described during SSZ treatment.

SSZ is safe during pregnancy but may induce oligospermia in males. Caution should be undertaken when breastfeeding (concerning potentially high concentrations of sulfapyridine in breast milk) (21). Initial blood cell count and liver tests and periodic evaluations are usually sufficient for preventing the serious adverse events of SSZ (10,20-22). 
Hydroxychloroquine. The use of HCQ as monotherapy has moderate efficacy for the treatment of RA. It is usually used in combination with other DMARDs, as 'triple therapy': MTX, SSZ and HCQ (21). Common adverse reactions are gastrointestinal (nausea, anorexia), cutaneous (rash), ocular retinopathy, although rare, but require screening in susceptible patients) (21).

Biologic therapy for RA. The better understanding of the immunopathogenic mechanisms involved in the genesis of RA (pro-inflammatory cytokines, costimulation between antigen-presenting cells and $\mathrm{T}$ cells, involvement of B cells) has contributed to the development of novel therapeutic agents, known as bDMARDs (23). These are classified into cytokine inhibitors (anti-TNF- $\alpha$, anti-IL- 6 and anti-IL-1 agents) and non-cytokine agents (anti-CD20 receptor on B cells and anti costimulation between antigen-presenting cells and $\mathrm{T}$ cells). All biologic agents have demonstrated their efficacy in clinical and functional improvement, in reduced radiographic damage and an improved quality of life for patients with RA.

Anti-TNF- $\alpha$ agents. TNF- $\alpha$ is one of the pivotal inflammatory cytokines, found in increased levels in the synovia and synovial fluid of patients with RA and it is involved in immune response, inflammation, cell infiltration, angiogenesis, and bone and cartilage destruction (24-26). This cytokine also plays important physiologic roles, particularly in relation to anti-tumour and anti-mycobacterial protection. TNF- $\alpha$ plays a major role in the formation of granuloma in tuberculosis (TB). TNF- $\alpha$ blockade may favour a new BK virus infection or reactivation of latent infection, which renders the rationale for very strict TB screening before beginning treatment with anti-TNF- $\alpha$ agents. Anti-TNF- $\alpha$ agents are either monoclonal antibodies (infliximab, adalimumab, golimumab, certolizumab) or soluble receptors (etanercept).

Infliximab. Infliximab is a chimeric monoclonal antibody combining the constant region of human IgG1 with the variable murine $\mathrm{Fv}$ region. The usual dose in the treatment of $\mathrm{RA}$ is $3 \mathrm{mg} / \mathrm{kg}$ via intravenous infusion at weeks 0,2 and 6 , and every 8 weeks thereafter. The dose may be increased to $7-10 \mathrm{mg} / \mathrm{kg}$ or the interval between infusions may be shortened to 4-6 weeks.

The Anti-Tumor Necrosis Factor Trial in Rheumatoid Arthritis with Concomitant Therapy (ATTRACT) study demonstrated that infliximab in combination with MTX is more effective than MTX alone in decreasing clinical signs and symptoms, in improving physical function and the quality of life, as well as in reducing structural damage $(27,28)$. These results have been validated by numerous studies that confirmed the long-term positive results of treatment with infliximab (28-30).

Adalimumab. Adalimumab is a fully human $\mathrm{IgG} 1$ monoclonal anti-TNF- $\alpha$ antibody which is administered subcutaneously at the dose of $40 \mathrm{mg}$ every 2 weeks.

The anti-TNF Research Study Program of the Monoclonal Antibody D2E7 in Rheumatoid Arthritis (ARMADA) study demonstrated the favourable effects of treatment with adalimumab in combination with MTX concerning all clinical and radiological variables (10). Other studies have also demonstrated the same favourable clinical and radiological effects and the safety of the use of adalimumab + MTX (or other DMARDs) for the treatment of RA in the advanced and early stages, for short-term (24 weeks) or long-term follow-up (31-35).

Golimumab. Golimumab is a fully human monoclonal anti-TNF- $\alpha$ antibody which is administered subcutaneously at the dose of $50 \mathrm{mg}$ once a month. The evaluatoin of golimumab has been very complex, involving patients who are DMARD-naïve to insufficient responders to MTX treatment and anti TNF- $\alpha$ treatment failures. Golimumab has been shown to have the ability to improve the symptoms associated with RA and physical function, as well as to attenuate short- and long-term structural damage $(36,37)$.

Certolizumab. Certolizumab is derived from a human monoclonal anti-TNF- $\alpha$ antibody, only retaining the latter's Fab fragment of an IgG molecule, and is polyethylene glycol (PEG)coated. Certolizumab is administered subcutaneously at the dose of $200 \mathrm{mg}$ every 2 weeks. The pegylated molecule of certolizumab offers important biological properties: a greater molecular weight with a prolonged half-life, the decreased penetration to normal tissue and the increased penetration to inflamed tissue, the inhibition of mast cell degranulation, the reduction of injection site-related adverse events and no placenta passage (38).

RAPID I and RAPID II studies have demonstrated the clinical and radiological efficacy of certolizumab in patients with RA who are unresponsive to MTX $(39,40)$. In addition, it has been demonstrated that certolizumab can be effective as a monotherapy for RA (41).

Etanercept. Etanercept is a recombinant molecule generated through the fusion of 2 identical chains of TNF- $\alpha$ receptors (p75-type II receptor) with a Fc fragment of an IgG1 human molecule. Etanercept is administered subcutaneously at the dose $50 \mathrm{mg}$ once a week.

Etanercept is a binding soluble TNF- $\alpha$, which blocks the interaction of TNF- $\alpha$ with specific receptors on target cells. Etanercept only binds circulating TNF- $\alpha$ and not the TNF- $\alpha$ membrane, resulting in milder TNF blockade. Etanercept also binds to TNF- $\beta$ (monoclonal anti-TNF- $\alpha$ antibodies only bind to TNF- $\alpha$ ). Etanercept has undergone extensive study, and has proven to be effective in combination with MTX or as monotherapy for the treatment of early-stage RA, and in MTX-naïve and in patients with RA who are unresponsive to MTX treatment. The TEMPO study (trial of etanercept and MTX with radiographic patient outcomes) demonstrated good clinical and radiological efficacy in combination with MTX (42-44).

The overall safety of anti-TNF therapy is considered satisfactory, with the most important adverse events including: i) an increased risk of infections (TB is of most concern); ii) an increased risk of cancer (however, clinical studies and registry data have indicated a similar cancer risk in patients with RA on anti-TNF treatments as compared to cancer risk in all patients with RA, with a possibly slight increase in the risk of lymphoma); iii) the aggravation of heart failure, anti-TNF treatments being contraindicated in patients with heart failure [New York Heart Association (NYHA) classes III and IV]; iv) demyelinating diseases (rare); v) the development of anti-dsDNA antibodies and even lupus-like syndrome; vi) allergic reactions; and vi) immunogenicity, with the development of anti-drug antibodies $(45,46)$.

In spite of the excellent overall efficacy of anti-TNF treatment, $35-40 \%$ of patients with RA are not responsive to 
this therapy and should be treated using biologic drugs with different actions.

IL-6 blockade. IL-6 is a pro-inflammatory cytokine with an important role in local and systemic RA pathogenic mechanisms. IL-6 stimulates the activation, differentiation and proliferation of B lymphocytes, IgG synthesis, lymphocyte T helper and cytotoxic differentiation and IL-17 production, and is also involved in acute and chronic inflammation, and prolonged immune response. As regards joints, IL-6 contributes to synovial cell proliferation, angiogenesis, the formation of articular pannus, bone and cartilage destruction. IL-6 systemic effects are also important in RA: the stimulation of the hepatic production of acute phase reactants, anaemia by the stimulation of hepatic hepcidin production (with the subsequent blockade of iron in macrophages), fatigue by affecting the hypothalamus-hypophysis system, increased cardiovascular risk through alterations in lipid metabolism and pro-inflammatory effects.

Tocilizumab. Tocilizumab is a monoclonal anti-IL-6 receptor antibody. By binding the Il- 6 receptor, it blocks the effects of IL-6. Tocilizumab is administered by intravenous infusion at the dose of $8 \mathrm{mg} / \mathrm{kg}$, once a month. Tocilizumab has been proven to be effective in various clinical trials on patients who are MTX-naïve, MTX-resistant and unresponsive to anti-TNF therapy. In combination with MTX and also as a monotherapy, treatment with tocilizumab leads to an improvement in the clinical symptoms, also halting radiologic progression, thus rendering biologic therapy with the strongest evidence of efficacy in monotherapy (47-50). The main adverse events of tocilizumab treatment include infections, diverticulitis, dyslipidemia, elevations in hepatic enzyme levels and neutropenia.

IL-1 blockade. IL-1 is a pro-inflammatory cytokine with many effects similar to those of TNF- $\alpha$. Currently, only one IL-1 blocker has been approved for the treatment of RA, namely anakinra, an IL-1 receptor antagonist. Although currently it is less commonly used due to its lower efficacy as compared to anti-TNF therapy, anakinra is administered via daily subcutaneous injections, which is highly unpopular with patients (51). The adverse events of IL-1 inhibitors include injection site reactions and possible infections (of the upper airways) (52).

\section{Non-cytokine biologic agents}

T lymphocyte blockade. Full $\mathrm{T}$ cell activation requires the costimulatory molecules, CD80/86 from antigen-presenting cells and CD28 from T lymphocytes. The binding of CD80/86 to CD28 leads to the activation of T lymphocytes and the binding of CD80/86 to the cytotoxic T lymphocyte-associated protein 4 (CTLA-4) receptor leads to the inhibition of $\mathrm{T}$ lymphocytes.

Abatacept is a soluble fully humanised recombinant receptor, formed by the fusion of the extracellular domain of CTLA-4 with a Fc fragment of human IgG1. Abatacept binds to $\mathrm{CD} 80 / 86$ from antigen-presenting cells, with greater affinity than to CD28, also blocking the costimulation and activation of $\mathrm{T}$ lymphocytes. The complex activity of $\mathrm{T}$ lymphocytes is not completely blocked, as by selectively binding CD80/86, abatacept allows other approaches for T lymphocyte activation, which makes it the first biologic therapy able to modulate
T lymphocyte activity. Abatacept is administered via intravenous infusion (500-1,000 mg at weeks 0, 2 and 4, and monthly thereafter) and via subcutaneous injection (125 mg, once a week). Randomised clinical trials have demonstrated that, in combination with MTX, abatacept is very effective in the short- and long-term treatment of patients with RA who are MTX-naïve and who are resistant to MTX, and that treatment with abatacept improves clinical manifestations and blocks structural destruction in a manner comparable with antiTNF therapy $(53,54,55)$. The main adverse events associated with abatacept are infusion-related reactions, susceptibility to infections and a reduced protective humoral response to vaccines (53).

B lymphocyte blockade. B lymphocytes are crucial for the pathogenic mechanisms of RA, acting as producers of cytokines and autoantibodies, and also of antigen-presenting cells and activators of T lymphocyte (54). CD20 is a receptor found on B lymphocyte membrane, but not on stem cells and plasmocytes. Treatment with monoclonal anti-CD20 antibody leads to a depletion of peripheral B lymphocytes by cytotoxicity, complementing activation and inducing apoptosis (56).

Rituximab. Rituximab is a chimeric monoclonal antiCD20 antibody initially used in the treatment of non-Hodgkin lymphoma. Clinical trials have proven that rituximab is highly effective in combination with MTX in the treatment of RA by improving clinical manifestations and blocking radiological progression (57-59). Rituximab is administered via intravenous infusion, and one treatment cycle consisting of two $1,000 \mathrm{mg}$ infusions at 2-week intervals, repeated after at least 6 months.

The rituximab safety profile is very good, the most frequent adverse events being related to infusion reactions and a slight increase in the number of infections (44). Guidelines indicate rituximab as second-line biologic treatment for patients with RA who are unresponsive to anti-TNF therapy; however, in particular clinical situations (recent lymphoma, latent TB with contraindication of prophylaxis with isoniazid) rituximab may be used as first-line biologic treatment (50).

The European League Against Rheumatism (EULAR) guidelines for the treatment of RA recommend biologic treatment with TNF- $\alpha$ blockers, tocilizumab or abatacept for patients who are unresponsive to at least one DMARD. In the case of ineffective first-line biologic treatment, this should be changed to another biologic medication of the same or different class.

New emerging therapies are represented by kinase inhibitors. Tofacitinib (Xeljanz) is a JAK inhibitor with comparable efficacy to TNF blockers (60). The associated adverse reactions are gastrointestinal and infections (an increased risk of herpes zoster infection).

\section{Conclusions}

The treatment of RA may be a challenge due to the complexity of the disease, the presence of comorbidities in the majority of patients, the duration of treatment and the frequency of adverse reactions of the drugs. The selection of the optimal treatment for RA should be based on guidelines and recommendations, but also on clinical particular aspects and patient preferences. RA requires aggressive therapies and the 'treat to target' strategy is 
effective in controlling the disease and achieving remission. At the same time, pharmacological interventions have a tremendous impact on the disease and on patients. Patients must be monitored with caution in clinical, biologic and imagistic aspects. The evaluation of periodic liver function (including serologic markers for viral hepatitis), renal evaluation, pulmonary evaluation with the Quantiferon TB Gold Test and radiologic imaging must be a rule in the evaluation of RA treatment. The aggravation of heart failure and demyelinating diseases, as well as the possibility of an increased risk of cancer during biologic therapy (although unconfirmed by registry data) are important issues which require in-depth investigations.

The use of biologic agents on wide scale has significantly changed the evolution of RA, but has also led to a brand new pathology. There are currently novel therapeutic targets under investigation, as there are still unmet needs in the management of RA, both in terms of efficacy and in reducing adverse events.

\section{References}

1. Geraldino-Pardilla L and Bathow JM: Management of rheumatoid arthritis: synovitis. In: Rheumatology. Hochberg MC, Silman AJ, Smolen JS, Weinblatt ME and Weisman MH (eds). 6th edition. Mosby Elsevier, Philadelphia, PA, pp802-807, 2015.

2. Smolen JS, Landewé R, Breedveld FC, Dougados M, Emery P, Gaujoux-Viala C, Gorter S, Knevel R, Nam J, Schoels M, et al: EULAR recommendations for the management of rheumatoid arthritis with synthetic and biological disease-modifying antirheumatic drugs. Ann Rheum Dis 69: 964-975, 2010.

3. Singh JA, Furst DE, Bharat A, Curtis JR, Kavanaugh AF, Kremer JM, Moreland LW, O'Dell J, Winthrop KL et al: 2012 update of the 2008 American College of Rheumatology recommendations for the use of disease-modifying antirheumatic drugs and biologic agents in the treatment of rheumatoid arthritis. Arthritis Care Res (Hoboken) 64: 625-639, 2012.

4. Patrono C: Non-steroidal anti-inflammatory drugs. In: Rheumatology. Hochberg MC, Silman AJ, Smolen JS, Weinblatt ME and Weisman MH (eds). 6th edition. Mosby Elsevier, Philadelphia, PA, pp415-422, 2015.

5. Saag K and Buttgereit F: Systemic glucocorticoids. In: Rheumatology. Hochberg MC, Silman AJ, Smolen JS, Weinblatt ME and Weisman MH (eds). 6th edition. Mosby Elsevier, Philadelphia, PA, pp423-431, 2015.

6. Buttgereit F, da Silva JA, Boers M, Burmester GR, Cutolo M, Jacobs J, Kirwan J, Köhler L, Van Riel P, Vischer T, et al Standardised nomenclature for glucocorticoid dosages and glucocorticoid treatment regimens: current questions and tentative answers in rheumatology. Ann Rheum Dis 61: 718-722, 2002.

7. Grigor C, Capell H, Stirling A, McMahon AD, Lock P, Vallance R, Kincaid W and Porter D: Effect of a treatment strategy of tight control for rheumatoid arthritis (the TICORA study): a single-blind randomised controlled trial. Lancet 364: 263-269, 2004

8. Johnsen AK and Weinblatt ME: Methotrexate. In: Rheumatology. Hochberg MC, Silman AJ, Smolen JS, Weinblatt ME and Weisman MH (eds). 6th edition. Mosby Elsevier, Philadelphia, PA, pp443-449, 2015.

9. McInnes IB, Jacobs JWG, Woodburn J and van Laar JM Treatment of rheumatoid arthritis. In: Eular Compendium on Rheumatic Diseases. Bijlsma JW (ed). BMJ Publishing Group and European League against Rheumatism, pp83-86, 2009.

10. Battistone MJ and Williams HJ: Disease-modifying antirheumatic drugs 3: methotrexate. In: Rheumatology. Hochberg MC, Silman AJ, Smolen JS, Weinblatt ME and Weisman MH (eds). 4th edition. Mosby Elsevier, Philadelphia, PA, pp449-457, 2008.

11. Johnston A, Gudjonsson JE, Sigmundsdottir H, Ludviksson BR and Valdimarsson H: The anti-inflammatory action of methotrexate is not mediated by lymphocyte apoptosis, but by the suppression of activation and adhesion molecules. Clin Immunol 114: 154-163, 2005.

12. Cutolo M, Sulli A, Pizzorni C, Seriolo B and Straub RH: Anti-inflammatory mechanisms of methotrexate in rheumatoid arthritis. Ann Rheum Dis 60: 729-735, 2001.
13. Wang Z, Chen Z, Yang S, Wang Y, Yu L, Zhang B, Rao Z, Gao J and Tu S: NMR-based metabolomic analysis for identifying serum biomarkers to evaluate methotrexate treatment in patients with early rheumatoid arthritis. Exp Ther Med 4: 165-171, 2012.

14. Kremer JM, Alarcón GS, Lightfoot RW Jr, Willkens RF, Furst DE, Williams HJ, Dent PB and Weinblatt ME; American College of Rheumatology: Methotrexate for rheumatoid arthritis. Suggested guidelines for monitoring liver toxicity. Arthritis Rheum 37: 316-328, 1994.

15. Cannon G, Sciff M and Strand V and Holden W: Hepatic adverse events and other toxicity during treatment with leflunomide, methotrexate, other disease-modifying antirheumatic drugs (DMARDs), and combination DMARD therapy: Comparison to NSAIDS alone and adjustment for comorbidities cathegory. Arthritis Rheum 46 (Suppl): Abs S357, 2002.

16. O'Dell JR: Methotrexate, Leflunomide, and Combination Therapies. In: Kelley's Textbook of Rheumatology. Ruddy S (ed). WB Saunders Company, Philadelphia, PA, pp906-910, 2005.

17. Hampson R, Madhok R and McInnes I: Methotrexate and sulfasalazine combination therapy (MASCOT) is more effective than either drug alone in patients with a sub-optimal response to sulfasalazine monotherapy: A double blind placebo randomised controlled trial (RCT). Ann Rheum Dis 64 (suppl 3): 456-457, 2005.

18. Haraoui B: Leflunomide. In: Rheumatology. Hochberg MC, Silman AJ, Smolen JS, Weinblatt ME and Weisman MH (eds). 6th edition. Mosby Elsevier, Philadelphia, PA, pp451-45, 2015.

19. Keystone E and Haraoui B: Disease-modifying antirheumatic drugs 4: leflunomide. In: Rheumatology. Hochberg MC, Silman AJ, Smolen JS, Weinblatt ME and Weisman MH (eds). 4th edition. Mosby Elsevier, Philadelphia, PA, pp461-468, 2008.

20. Capell HA and Madhok R: Disease-modifying antirheumatic drugs 2: sulfasalazine. In: Rheumatology. Hochberg MC, Silman AJ, Smolen JS, Weinblatt ME and Weisman MH (eds). 4th edition. Mosby Elsevier, Philadelphia, PA, pp437-445, 2008.

21. Bykerk V: Non-immunosuppressive disease-modifying antirheumatic drugs. In: Rheumatology. Hochberg MC, Silman AJ, Smolen JS, Weinblatt ME and Weisman MH (eds). 6th edition. Mosby Elsevier, Philadelphia, PA, pp436-437, 2015.

22. Gordon DA and Klinkhoff AV: Second Line Agents. In: Kelley's Textbook of Rheumatology. Ruddy S (ed). WB Saunders Company, Philadelphia, PA, pp877-899, 2005.

23. Fleischmann RM: Biologic therapy in rheumatoid arthritis. Rheumatol News (suppl 1): 3-4, 2002

24. Choy EH and Panayi GS: Cytokine pathways and joint inflammation in rheumatoid arthritis. N Engl J Med 344: 907-916, 2001.

25. Dinarello CA and Moldawer LL (eds). Proinflammatory and antiinflammatory cytokines in rheumatoid arthritis: A primer for clinicians. 2nd edition. Amgen, Inc., Thousand Oaks, CA, 2000.

26. Lam J, Abu-Amer Y, Nelson CA, Fremont DH, Ross FP and Teitelbaum SL: Tumour necrosis factor superfamily cytokines and the pathogenesis of inflammatory osteolysis. Ann Rheum Dis 61 (Suppl 2): ii82-ii83, 2002.

27. Maini R, St Clair EW, Breedveld F, Furst D, Kalden J, Weisman M, Smolen J, Emery P, Harriman G, Feldmann M, et al; ATTRACT Study Group: Infliximab (chimeric anti-tumour necrosis factor alpha monoclonal antibody) versus placebo in rheumatoid arthritis patients receiving concomitant methotrexate: A randomised phase III trial. Lancet 354: 1932-1939, 1999.

28. Maini RN, Breedveld FC, Kalden JR, Smolen JS, Furst D, Weisman MH, St Clair EW, Keenan GF, van der Heijde D, Marsters PA, et al; Anti-Tumor Necrosis Factor Trial in Rheumatoid Arthritis with Concomitant Therapy Study Group: Sustained improvement over two years in physical function, structural damage, and signs and symptoms among patients with rheumatoid arthritis treated with infliximab and methotrexate. Arthritis Rheum 50: 1051-1065, 2004.

29. Smolen JS, Han C, Bala M, Maini RN, Kalden JR, van der Heijde D, Breedveld FC, Furst DE and Lipsky PE; ATTRACT Study Group: Evidence of radiographic benefit of treatment with infliximab plus methotrexate in rheumatoid arthritis patients who had no clinical improvement: A detailed subanalysis of data from the anti-tumor necrosis factor trial in rheumatoid arthritis with concomitant therapy study. Arthritis Rheum 52: 1020-1030, 2005.

30. Nam JL, Ramiro S, Gaujoux-Viala C, Takase K, Leon-Garcia M, Emery P, Gossec L, Landewe R, Smolen JS and Buch MH: Efficacy of biological disease-modifying antirheumatic drugs: a systematic literature review informing the 2013 update of the EULAR recommendations for the management of rheumatoid arthritis. Ann Rheum Dis 73: 516-528, 2014. 
31. Weinblatt ME, Keystone EC, Furst DE, Moreland LW, Weisman MH, Birbara CA, Teoh LA, Fischkoff SA and Chartash EK: Adalimumab, a fully human anti-tumor necrosis factor alpha monoclonal antibody, for the treatment of rheumatoid arthritis in patients taking concomitant methotrexate: The ARMADA trial. Arthritis Rheum 48: 35-45, 2003.

32. van de Putte LB, Atkins C, Malaise M, Sany J, Russell AS, van Riel PL, Settas L, Bijlsma JW, Todesco S, Dougados M, et al: Efficacy and safety of adalimumab as monotherapy in patients with rheumatoid arthritis for whom previous disease modifying antirheumatic drug treatment has failed. Ann Rheum Dis 63: 508-516, 2004

33. Keystone EC, Kavanaugh AF, Sharp JT, Tannenbaum H, Hua Y, Teoh LS, Fischkoff SA and Chartash EK: Radiographic, clinical, and functional outcomes of treatment with adalimumab (a human anti-tumor necrosis factor monoclonal antibody) in patients with active rheumatoid arthritis receiving concomitant methotrexate therapy: A randomized, placebo-controlled, 52-week trial. Arthritis Rheum 50: 1400-1411, 2004.

34. Weinblatt ME, Keystone EC, Furst DE, Kavanaugh AF Chartash EK and Segurado OG: Long term efficacy and safety of adalimumab plus methotrexate in patients with rheumatoid arthritis: ARMADA 4 year extended study. Ann Rheum Dis 65 753-759, 2006

35. Breedveld FC, Weisman MH, Kavanaugh AF, Cohen SB Pavelka K, van Vollenhoven R, Sharp J, Perez JL and Spencer-Green GT: The PREMIER study: A multicenter, randomized, double-blind clinical trial of combination therapy with adalimumab plus methotrexate versus methotrexate alone or adalimumab alone in patients with early, aggressive rheumatoid arthritis who had not had previous methotrexate treatment. Arthritis Rheum 54: 26-37, 2006.

36. Keystone EC, Genovese MC, Klareskog L, Hsia EC, Hall ST, Miranda PC, Pazdur J, Bae SC, Palmer W, Zrubek J, et al: Golimumab, a human antibody to TNF- $\alpha$ given by monthly subcutaneous injections, in active rheumatoid arthritis despite methotrexate: the GO-FORWARD Study. Ann Rheum Dis 68 789-796, 2009.

37. Kay J and Rahman MU: Golimumab: A novel human anti-TNF-o monoclonal antibody for the treatment of rheumatoid arthritis, ankylosing spondylitis, and psoriatic arthritis. Core Evid 4: 159-170, 2009.

38. McDonnell T, Ioannou Y and Rahman A: PEGylated drugs in rheumatology - why develop them and do they work? Rheumatology (Oxford) 53: 391-396, 2014

39. Keystone E, Heijde D, Mason D Jr, Landewé R, Vollenhoven RV, Combe B, Emery P, Strand V, Mease P, Desai C, et al: Certolizumab pegol plus methotrexate is significantly more effective than placebo plus methotrexate in active rheumatoid arthritis: Findings of a fifty-two-week, phase III, multicenter, randomized, double-blind, placebo-controlled, parallel-group study. Arthritis Rheum 58: 3319-3329, 2008.

40. Smolen J, Landewé RB, Mease P, Brzezicki J, Mason D, Luijtens K, van Vollenhoven RF, Kavanaugh A, Schiff M, Burmester GR, et al: Efficacy and safety of certolizumab pegol plus methotrexate in active rheumatoid arthritis: The RAPID 2 study. A randomised controlled trial. Ann Rheum Dis 68: 797-804, 2009.

41. Fleischmann R, Vencovsky J, van Vollenhoven RF, Borenstein D, Box J, Coteur G, Goel N, Brezinschek HP, Innes A and Strand V: Efficacy and safety of certolizumab pegol monotherapy every 4 weeks in patients with rheumatoid arthritis failing previous disease-modifying antirheumatic therapy: The FAST4WARD study. Ann Rheum Dis 68: 805-811, 2009.

42. Klareskog L, van der Heijde D, de Jager JP, Gough A, Kalden J, Malaise M, Martín Mola E, Pavelka K, Sany J, Settas L, et al; TEMPO (Trial of Etanercept and Methotrexate with Radiographic Patient Outcomes) study investigators: Therapeutic effect of the combination of etanercept and methotrexate compared with each treatment alone in patients with rheumatoid arthritis: Double-blind randomised controlled trial. Lancet 363: 675-681, 2004

43. Emery P, Breedveld F, van der Heijde D, Ferraccioli G, Dougados M, Robertson D, Pedersen R, Koenig AS and Freundlich B; Combination of Methotrexate and Etanercept in Early Rheumatoid Arthritis Trial Group: Two-year clinical and radiographic results with combination etanercept-methotrexate therapy versus monotherapy in early rheumatoid arthritis: a two-year, double-blind, randomized study. Arthritis Rheum 62 674-682, 2010
44. Cañete JD and Pablos JL: Biologic therapy in rheumatoid arthritis. Curr Top Med Chem 13: 752-759, 2013

45. Ramiro S, Gaujoux-Viala C, Nam JL, Smolen JS, Buch M, Gossec L, van der Heijde D, Winthrop K and Landewé R: Safety of synthetic and biological DMARDs: a systematic literature review informing the 2013 update of the EULAR recommendations for management of rheumatoid arthritis. Ann Rheum Dis 73: 529-535, 2014

46. Leombruno JP, Einarson TR and Keystone EC: The safety of anti-tumour necrosis factor treatments in rheumatoid arthritis: meta and exposure-adjusted pooled analyses of serious adverse events. Ann Rheum Dis 68: 1136-1145, 2009.

47. Rueda Gotor J and Blanco Alonso R: Tocilizumab in rheumatoid arthritis. Reumatol Clin 6S3: S29-S32, 2011 (In Spanish).

48. Jones G, Sebba A, Gu J,Lowenstein MB, Calvo A, Gomez-Reino JJ, Siri DA, Tomsic M, Alecock E, Woodworth T, et al: Comparison of tocilizumab monotherapy versus methotrexate monotherapy in patients with moderate to severe rheumatoid arthritis: the AMBITION study. Ann Rheum Dis 69: 88-96, 2010.

49. Kaufmann J, Feist E, Roske AE and Schmidt WA: Monotherapy with tocilizumab or TNF-alpha inhibitors in patients with rheumatoid arthritis: efficacy, treatment satisfaction, and persistence in routine clinical practice. Clin Rheumatol 32: 1347-1355, 2013.

50. Smolen JS, Landewé R, Breedveld FC, Buch M, Burmester G, Dougados M, Emery P, Gaujoux-Viala C, Gossec L, Nam J, et al: EULAR recommendations for the management of rheumatoid arthritis with synthetic and biological disease-modifying antirheumatic drugs: 2013 update. Ann Rheum Dis 73: 492-509, 2014.

51. Meier FM, Frerix M, Hermann W and Müller-Ladner U: Current immunotherapy in rheumatoid arthritis. Immunotherapy 5: 955-974, 2013

52. Gabay C: Cytokine neutralizers: interleukin-1 inhibitors. In: Rheumatology. Hochberg MC, Silman AJ, Smolen JS, Weinblatt ME and Weisman MH (eds). 6th edition. Mosby Elsevier, Philadelphia, PA, pp479-483, 2015.

53. Choi EH: T-cell costimulation and other directed therapies. In: Rheumatology. Hochberg MC, Silman AJ, Smolen JS, Weinblatt ME and Weisman MH (eds). 6th edition. Mosby Elsevier, Philadelphia, PA, pp468-470, 2015.

54. Caporali R, Bugatti S, Cavagna L, Antivalle $M$ and Sarzi-Puttini P: Modulating the co-stimulatory signal for T cell activation in rheumatoid arthritis: Could it be the first step of the treatment? Autoimmun Rev 13: 49-53, 2014.

55. Weinblatt ME, Schiff M, Valente R, van der Heijde D, Citera G, Zhao C, Maldonado M and Fleischmann R: Head-to-head comparison of subcutaneous abatacept versus adalimumab for rheumatoid arthritis: Findings of a phase IIIb, multinational, prospective, randomized study. Arthritis Rheum 65: 28-38, 2013.

56. Edwards JC and Cambridge G: Sustained improvement in rheumatoid arthritis following a protocol designed to deplete B lymphocytes. Rheumatology (Oxford) 40: 205-211, 2001.

57. Edwards JC, Szczepanski L, Szechinski J, Filipowicz-Sosnowska A, Emery P, Close DR, Stevens RM and Shaw T: Efficacy of B-cell-targeted therapy with rituximab in patients with rheumatoid arthritis. N Engl J Med 350: 2572-2581, 2004.

58. Emery P, Fleischmann R, Filipowicz-Sosnowska A, Schechtman J, Szczepanski L, Kavanaugh A, Racewicz AJ, van Vollenhoven RF, Li NF, et al: The efficacy and safety of rituximab in patients with active rheumatoid arthritis despite methotrexate treatment: results of a phase IIB randomized, double-blind, placebo-controlled, dose-ranging trial. Arthritis Rheum 54: 1390-1400, 2006.

59. VitalEM,Dass S and Emery P: B-cell depletion.In: Rheumatology. Hochberg MC, Silman AJ, Smolen JS, Weinblatt ME and Weisman MH (eds). 6th edition. Mosby Elsevier, Philadelphia, PA, pp472-477, 2015.

60. Van Vollenhoven RF: Kinase inhibition: a new therapeutic principle in rheumatology. In: Rheumatology. Hochberg MC, Silman AJ, Smolen JS, Weinblatt ME and Weisman MH (eds). 6th edition. Mosby Elsevier, Philadelphia, PA, pp511-516, 2015. 